\title{
LETTER FROM THE CENTRE
}

The Centre is now officially ten years old, for on November 23, we celebrated our second lustrum with the publication of the fifth volume in our Comparative studies series, Colonial cities; Essays on Urbanism in a Colonial Context, edited by Robert Ross and Gerard Telkamp. (A fuller description of its contents is to be found in the advertisement at the back of this issue.) On this occasion, we also welcomed back H.L. Wesseling as chairman - the man who created the Centre. For the past triennium, his job was ably filled by Ivo Schöffer, whose skillful leadership and genial presence has left us in fine fettle and spirits for our second decade.

We wish to call your attention to a varied roster of articles, ranging from Alistair Hennessy's exciting and concrete essay on how insurrections in Spain's two remaining colonies at the end of the nineteenth century blended (and became confused) with the Spanish-American War of 1898, to two theoritical articles, one by Jan Kiniewicz and the other by André Wink. To illustrate the Wink article, incidentally, we unearthed a rare 1937 photograph of J.C. van Leur, its subject - probably the first his many readers have ever seen.

And finally, we have included an interview with one of our favourite historians, the good-humoured and seemingly omniscient Jan Vansina, who spent only a few hours in Leiden, but allowed us to closed him in an office for two of them, within sight of the train we almost made him miss. But we think it affords a true glimpse of a fascinating personality. 